\title{
A vital role for complement in heart disease
}

Knut T. Lappegard, Peter Gaffed, Lena Jonasson, Terje Espevik, Pal Aukrust, Arne Yndestad,

Tom E. Mollnes and Anders Hovland

Linköping University Post Print

Tweet

N.B.: When citing this work, cite the original article.

Original Publication:

Knut T. Lappegard, Peter Gaffed, Lena Jonasson, Terje Espevik, Pal Aukrust, Arne Yndestad, Tom E. Mollnes and Anders Hovland, A vital role for complement in heart disease, 2014, Molecular Immunology, (61), 2, 126-134.

http://dx.doi.org/10.1016/j.molimm.2014.06.036

Copyright: Elsevier

http://www.elsevier.com/

Postprint available at: Linköping University Electronic Press

http://urn.kb.se/resolve?urn=urn:nbn:se:liu:diva-111600 


\section{A vital role for complement in heart disease}

Knut T. Lappegård, MD, $\mathrm{PhD}{ }^{1,2}$, Peter Garred, $\mathrm{MD}, \mathrm{PhD}^{3}$, Lena Jonasson, MD, PhD ${ }^{4}$, Terje Espevik, PhD ${ }^{5}$, Pål Aukrust, MD, PhD ${ }^{6,7}$ Arne Yndestad $\mathrm{PhD}{ }^{6,7}$, Tom E. Mollnes MD, PhD $2,5,7,8,9$ and Anders Hovland, MD, PhD ${ }^{1,2}$

${ }^{1}$ Coronary Care Unit, Division of Internal Medicine, Nordland Hospital, Bodø, Norway.

${ }^{2}$ Institute of Clinical Medicine, University of Tromsø, Tromsø, Norway.

${ }^{3}$ Laboratory of Molecular Medicine, Department of Clinical Immunology, section 7631 Rigshospitalet, Copenhagen University Hospital, Copenhagen, Denmark.

${ }^{4}$ Department of Medical and Health Sciences, Division of Cardiovascular Medicine, Linköping University, Linköping, Sweden.

${ }^{5}$ Centre of Molecular Inflammation Research, and Department of Cancer Research and Molecular Medicine, Norwegian University of Science and Technology, Trondheim, Norway.

${ }^{6}$ Research Institute of Internal Medicine and Section of Clinical Immunology and Infectious Diseases, Oslo University Hospital Rikshospitalet, Oslo, Norway.

7 K.J. Jebsen Inflammation Research Centre, University of Oslo, Oslo, Norway.

${ }^{8}$ Research Laboratory, Nordland Hospital, Bodø, Norway.

${ }^{9}$ Department of Immunology, Oslo University Hospital Rikshospitalet, Oslo, Norway. 
Corresponding author:

Anders Hovland

Coronary Care Unit, Division of Internal Medicine

Nordland Hospital, N-8092 Bodø, Norway

E-mail: anders.w.hovland@gmail.com

Telephone: +4775534000 , Telefax: +4775534742 


\begin{abstract}
Heart diseases are common and significant contributors to worldwide mortality and morbidity. During recent years complement mediated inflammation has been shown to be an important player in a variety of heart diseases. Despite some negative results from clinical trials using complement inhibitors, emerging evidence points to an association between the complement system and heart diseases. Thus, complement seems to be important in coronary heart disease as well as in heart failure, where several studies underscore the prognostic importance of complement activation. Furthermore, patients with atrial fibrillation often share risk factors both with coronary heart disease and heart failure, and there is some evidence implicating complement activation in atrial fibrillation. Moreover, Chagas heart disease, a protozoal infection, is an important cause of heart failure in Latin America, and the complement system is crucial for the protozoa-host interaction. Thus, complement activation appears to be involved in the pathophysiology of a diverse range of cardiac conditions. Determination of the exact role of complement in the various heart diseases will hopefully help to identify patients that might benefit from therapeutic complement intervention.
\end{abstract}

Keywords: Complement system, myocardial infarction, coronary heart disease, heart failure, atrial fibrillation, Chagas disease 


\section{Introduction}

Heart diseases are significant contributors to worldwide morbidity and mortality (Moran et al., 2014a). However, while mortality rates from coronary heart disease have declined over the last 30 years, the identification and treatment of unstable coronary lesions is still a challenge. Moreover, due to the growing and ageing population, there is an increase in the global burden of coronary heart disease (Moran et al., 2014b). There is also an increase in heart failure as a result of coronary heart disease, dilated cardiomyopathy, hypertension and type 2 diabetes (Moran et al., 2014b). Another cause of heart failure is Chagas disease, predominantly found in Latin America where it is caused by a parasitic infection (Bocchi et al., 2013). In 2012, the global cost of heart failure worldwide was estimated to 108 billion US dollars (Cook et al., 2014). Due to the elderly population, and paradoxically, the improved survival in coronary heart disease, the prevalence and mortality rates of atrial fibrillation are increasing as well (Chugh et al., 2014).

\subsection{The complement system}

The complement system consists of more than 40 soluble and membrane bound proteins. A substantial number are inhibitors, which are crucially important to keep the system under control during normal conditions. The system can be activated through three main pathways: classical-, lectin- and alternative pathway. I addition a direct activation of C5 without prior activation of C3 has been described (Huber-Lang et al., 2006). The different activation pathways converge in the common pathway with activation of C3 and C5 continuing to the terminal pathway with release of the biologically highly potent anaphylatoxin C5a and formation of the terminal C5b-9 complement complex (TCC). The terminal complement complex can appear as a soluble complex in the fluid phase (sC5b-9) or attack cell membranes as the membrane attack complex (MAC). The latter may either lead to lysis of bacteria and cells, or, if formed in sub-lytic amounts, to stimulation of the cell with subsequent release of inflammatory mediators. Recent studies suggest that complement also can be regarded as a surveillance system that quickly 
can be activated by sensing danger signals, both sterile and non-sterile, to the host and thereby contribute to maintain tissue homeostasis and promote tissue repair (Ricklin et al., 2010). On the other hand, undesired or uncontrolled complement activation can induce tissue damage and organ dysfunction in the host such as can be seen during septicemia and various autoimmune disorders (Barratt-Due et al., 2012).

\subsection{Inflammation and cardiovascular disease}

Atherosclerosis is a common chronic inflammatory disease of the arterial vasculature that is associated with lipid accumulation in the arterial wall with the bidirectional interaction between lipid and inflammation as a phenotypical hallmark. This process is the underlying pathology of major cardiovascular diseases, including coronary heart disease and heart failure (Hansson and Libby, 2006; Hansson and Hermansson, 2011). Modified lipoproteins and cholesterol crystals in the arterial wall are potentially dangerous stressors. The innate immune system initiates and orchestrates the immune response to these particles. In this "first line of defence" a variety of pattern recognition receptors are used, including cellular pattern recognition receptors such as scavenger receptors and Toll-like receptors (TLRs), and soluble pattern recognition receptors such as complement components. Oxidized low-density lipoprotein (LDL) is endocytosed by CD36 that among others coordinates the intracellular conversion of this ligand to cholesterol crystals (Sheedy et al., 2013). Phagocytosis of cholesterol crystals induces lysosomal damage that results in the activation of the NLRP3 inflammasome, with subsequent activation of caspase- 1 and secretion of IL-1 $\beta$ and IL-18 (Duewell et al., 2010). Recent data have demonstrated that the complement system can control several cellular processes involved in cholesterol crystal-induced inflammasome activation (Samstad et al., 2014).

Hence, there is considerable crosstalk between the different parts of the innate immune system in the atherosclerotic process. There is also an intensive crosstalk between the coagulation and the complement systems, 
and if uncontrolled this "immunothrombosis" may lead to thrombotic complications including myocardial infarction and stroke (Engelmann and Massberg, 2013). Inflammatory responses are also involved in the development and progression of heart failure, and again, innate immune responses and complement seem to participate in these responses.

In the current review we address the latest research on the importance of the complement system for the evolvement of different heart diseases with focus on coronary heart disease, heart failure, arrhythmias and Chagas disease (Figure 1). We also discuss complement inhibition in heart diseases, as well as the possibility of combined inhibition of complement and other components of innate immunity.

\section{Coronary heart diseases and the complement system}

Coronary heart disease is, in the great majority of cases, caused by atherosclerosis in the coronary arteries, and spans from silent ischemia, effort-induced angina pectoris, acute coronary syndromes (unstable angina and myocardial infarction) to sudden cardiac death. There is an important distinction both prognostically and therapeutically, between ST-elevation myocardial infarction (STEMI) and non-ST-elevation myocardial infarction. Innate immunity, including the complement system, is important in the formation of atherosclerotic plaques (Haskard et al., 2008; Hansson and Hermansson, 2011; Weber and Noels, 2011; Torzewski and Bhakdi, 2012). These plaques may be stable, characterized by a large fibrous cap, or unstable, where inflammatory cells and lipids dominate. While the former lesion may be associated with a narrow lumen giving rise to stable ischemic symptoms, the latter lesion is associated with plaque rupture and thrombus formation with subsequent development of an acute coronary syndrome.

2.1 Genetic studies on the complement system and risk of coronary heart disease 
The C4A and C4B genes code for C4, important in both the classical and the lectin pathways. Low C4B numbers are associated with increased short-term mortality in smoking myocardial infection patients (Blaskó et al., 2008). The mannose-binding lectin (MBL) 2 gene codes for $M B L$ in the lectin pathway. Øhlenschlager et al. and Siezenga et al. found that the $\mathrm{O} / \mathrm{O}$ genotype of MBL2, was associated with future risk of coronary heart disease in patients with systemic lupus erytmatosus and type 2 diabetes, respectively (Øhlenschlaeger et al., 2004; Siezenga et al., 2011). Alipour et al. did not find any association between MBL2 haplotypes and the progression of coronary heart disease in statin treated patients (Alipour et al., 2011). Vengen et al. have found that MBL2 gene variants with functional MBL deficiency were associated with increased risk for myocardial infarction in a population-based cohort of young individuals followed for 10 years (Vengen et al., 2012). Leban et al. recently described a strong relationship between the C3F allele of the C3 gene, coding for complement factor C3 of the common pathway, and risk of myocardial infarction (Leban et al., 2013). Factor $\mathrm{H}$ is a complement regulator, and polymorphisms, especially $\mathrm{Y} 402 \mathrm{H}$, in the Factor $\mathrm{H}$-gene is extensively studied and associated with age-related macular degeneration (Gehrs et al., 2010). There are conflicting results about the $\mathrm{Y} 402 \mathrm{H}$ polymorphisms and cardiovascular disease including myocardial infarction, but most studies find no association, so the importance of factor $\mathrm{H}$ variants in cardiovascular disease at present is unclear (Zee et al., 2006; Kardys et al., 2006; Nicaud et al., 2007; Stark et al., 2007; Sofat et al., 2010). Thus, some variants in genes encoding proteins of the complement system including MBL and C3 are associated with risk for coronary heart disease, while in others like factor $\mathrm{H}$ appear to be more uncertain.

\subsection{The complement system and myocardial ischemia-reperfusion injury}

The treatment of acute coronary heart disease has been substantially improved with the introduction of reperfusion strategies including fibrinolysis and percutaneous coronary intervention. However, reperfusion of the ischemic myocardium may itself cause damage to the heart. This ischemiareperfusion injury involves direct cardiomyocyte death and also myocardial 
stunning, arrhythmias and the "no reflow" phenomenon (Gerczuk and Kloner, 2012; Jennings 2013; Ovize et al., 2013). Several approaches including pre-, post-, and remote- ischemic conditioning and several pharmacological therapies including immune modulation have been promising in both preclinical and clinical models. However, there is currently no widely approved therapy that addresses this important clinical problem (Heusch 2013; Kloner 2013; Frangogiannis 2014). Experimental studies strongly implicate the complement system as pivotal in ischemia-reperfusion injury. However, the results from trials with specific complement inhibitors have thus far been disappointing (Banz and Rieben, 2012; Gorsuch et al., 2012; Timmers et al., 2012).

\subsection{Evidence for complement activation in coronary heart disease}

More than four decades ago Hill and Ward induced acute myocardial infarction in rats by ligating a coronary artery, and demonstrated the occurrence of C3-convertase in the infarcted myocardium, indeed confirming in situ complement activation (Hill and Ward, 1971). Since then, several studies have underlined the importance of the complement system in coronary heart disease. There are some indications that the lectin pathway plays a more prominent role in the induction of complement activation than the classical and the alternative, during ischemia-reperfusion injury (Jordan et al., 2001; Walsh et al., 2005; Busche et al., 2009). Trendelenburg et al. discovered that serum MBL of or below $100 \mathrm{ng} / \mathrm{ml}$, due to $\mathrm{MBL}$ deficiency, was associated with reduced mortality in patients with STEMI treated with primary percutaneous coronary intervention (Trendelenburg et al., 2010). In contrast, low concentration of the MBL serine proteases seems to be unfavourable. Thus, Zhang et al. detected that MBL associated serine protease 2 (MASP-2) was reduced in peripheral blood of myocardial infarction patients compared to controls (Zhang et al., 2013). They extended those findings to a coronary artery bypass grafting (CABG) setting, in which coronary levels of reduced MASP-2 correlated with larger myocardial necrosis measured by serum troponin-I levels (Zhang et al., 2013). This finding has later been confirmed (Frauenknecht et al., 2013). The latter group also 
measured an increase in plasma MASP-1 in acute myocardial infarction, a finding recently reproduced by others (Frauenknecht et al., 2013; Holt et al., 2014). Collectively these data indicate that genetic low MBL is beneficial by reduced activation potential of the lectin pathway, whereas the consequences of the changes in MASPs are more uncertain.

Moreover, Horvath et al. found evidence of classical activation in stable coronary heart disease, evidenced by increased $\mathrm{C} 1 \mathrm{rsC} 1$-inhibitor complexes (Horváth et al., 2012). Another group, using a proteomic approach, showed a decrease in inflammatory proteins in acute myocardial infarction after the acute phase, however there was an increase in serum amyloid P-component, a known activator of the classical pathway (Cubedo et al., 2013). Recently, Kishida et al. demonstrated elevated plasma $\mathrm{C} 1 \mathrm{q}$ in acute coronary syndromes, and also an increase in the complex of adiponectin and $\mathrm{C} 1 \mathrm{q}$ (Kishida et al., 2014). So even if the lectin pathway seems involved in acute myocardial infarction, recent research has indicated a role for the classical pathway as well.

$\mathrm{C} 3$, the central component of all three activation pathways, is an acute phase response protein. Several studies have demonstrated that increased serum C3 and/or increased C3/C4 ratio are associated with increased risk in coronary heart disease (Széplaki et al., 2004; Palikhe et al., 2007). Engström et al. confirmed these findings, however they also detected that elevated levels of plasma C4 was associated with an increase in coronary events (Engström et al., 2007). The highly bioactive anaphylatoxins C3a and C5a, generated by activation of $\mathrm{C} 3$ and $\mathrm{C} 5$, are associated with increased risk in coronary heart disease (Speidl et al., 2005; Distelmaier et al., 2009), and C3aand $\mathrm{C5a}$ receptors are expressed in human coronary plaques (Oksjoki et al., 2007). Recently Nilsson et al. established that plasma C3, C4 and the activation fragment C3a-desArg were strongly related with adipose tissue volume and established risk factors for cardiovascular diseases (Nilsson et al., 2014). 
Hoffmeister et al. found that both C-reactive protein (CRP) and plasma sC5b9 were associated with unstable coronary disease (Hoffmeister et al., 2002). Ørn et al. demonstrated an increase in sC5b-9 two days after revascularization in STEMI, consistent with complement activation in the infarcted area (Ørn et al., 2009). It has later been confirmed that plasma sC5b-9 at hospital admittance is a negative prognostic factor in acute myocardial infarction (Lindberg et al., 2012; Mellbin et al., 2012).

Hence the different parts of the complement system play a role in both stable and unstable coronary heart disease. Recent research indicates that cholesterol crystals are important activators of the complement cascade (Samstad et al., 2014). Complement activation through both the classical and the lectin pathway seem involved, and the activation products C3a, C5a are sC5b-9 are all negative prognostic markers. Thus, several steps in the complement cascade are candidates for therapeutic intervention in acute coronary syndromes.

\subsection{Complement inhibition in coronary heart disease}

Animal models have emphasized the importance of the complement system in myocardial infarction, and pharmacological inhibition of the complement system has also shown promising results in experimental studies (del Balzo et al., 1985; Weisman et al., 1990; Fairweather et al., 2006; van der Pals et al., 2010; Mueller et al., 2013).

Human soluble complement receptor 1 , designated TP10, inhibits C3 activation, thus blocking the activation from all three initial pathways (Shandelya et al., 1993). Weisman et al. have demonstrated reduced myocardial infarction size, using TP10 in a rat ischemia-reperfusion model (Weisman et al., 1990). Lazar et al. studied the effects of TP10 in high-risk patients undergoing cardiac surgery, but even if complement activation was effectively suppressed by TP10, there was no reduction in the clinical composite primary endpoint (Lazar et al., 2004). However, there was a reduction in mortality and myocardial infarction size in males but not in 
females (Lazar et al., 2004; Lazar et al., 2007), suggesting that the effects of TP10 may be gender-related. These observations have not been further explored.

Almost two decades ago pexelizumab, a monoclonal antibody binding to and inhibiting the cleavage of $\mathrm{C} 5$, was developed using a recombinant technique (Thomas et al., 1996). Large scale clinical testing of pexelizumab in various settings of coronary heart disease has been performed, so far with disappointing results (Table 1).

Altogether, complement activation is clearly a participant in the evolvement of cardiac heart disease, including acute myocardial infarction and ischemiareperfusion injury. However, from a clinical point of view, it seems as if complement inhibition with pexelizumab has no effect on primary endpoints in STEMI patients. Martel et al. have tried to establish why pexelizumab failed to reduce the primary endpoint in the APEX-AMI study (APEX AMI Investigators 2007), and found that pexelizumab apparently reduced plasma C5a, but not the formation of sC5b-9, and thus not the downstream sub-lytic MAC inflammation (Martel et al., 2012). This activation probably occurred previous to the administration of the drug and thus the delayed administration could explain the lack of clinical benefit. However there seem to be a window of opportunity for complement inhibition in CABG patients. A post hoc analysis of the PRIMO-CABG study (Verrier et al., 2004) indicated benefit of pexelizumab in high-risk patients undergoing CABG (Haverich et al., 2006). Testa et al. performed a meta-analysis of the pexelizumab studies which indicated reduced mortality in CABG patients (Testa et al., 2008). The reason for clinical effect during CABG but not during STEMI, could be the known powerful complement activation that takes place during external circulation with heart-lung machines due to the surfaces of the tubing and bypass loops used, an activation more extensive than in the setting of STEMI (Edmunds 1998). Furthermore, the aspect of timing, i.e. when to administer the inhibitor in relation to the onset of the ischemic-reperfusion injury, may be a factor which allows for effect in controlled conditions, but precludes effect in an acute clinical setting. 


\section{Heart failure and the complement system}

In addition to ischemic heart disease, there are several other known causes of heart failure, including hypertension, valvular diseases and cardiomyopathy of unknown etiologies, often called idiopathic dilated cardiomyopathy. Heart failure development is characterized by several structural and cellular changes, commonly referred to as myocardial remodeling. This remodeling involves cardiomyocyte hypertrophy, ventricular dilation and fibrosis, and experimental and some clinical evidence implicates inflammatory mediators as important mediators of remodeling and heart failure development (Yndestad et al., 2007).

\subsection{Complement activation in heart failure}

More than a decade ago, Aukrust et al. demonstrated increased complement activation in patients with congestive heart failure, including both patients with idiopathic dilated and ischemic cardiomyopathies (Aukrust et al., 2001).

During treatment with high-dose intravenous immunoglobulin they noted an increase in left ventricular ejection fraction and an increase in complement activation, the latter a known effect of intravenous immunoglobulin (Mollnes et al., 1997). Whether the increase in complement activation in these patients reflected a shift from tissue phase to the fluid phase or if it reflected a more general systemic increase in complement activation, e.g. induced by a chronic whole body ischemia, or release of alarmins, is unknown. It is also unclear whether these changes in complement activation in any way were directly involved in the change in ejection fraction.

Ficolins are recognition molecules in the lectin pathway. Schoos et al. found that plasma ficolin-2 combined with other lectin pathway proteins, including MBL and MBL/ficolin-associated Protein-1 were associated with larger left ventricular volumes following STEMI (Schoos et al., 2013). Prohászka et al. could not find any association between plasma ficolin-2 and heart failure, 
however they established an association between low levels of plasma ficolin3 and advanced heart failure, and they found that low levels of ficolin-3 was a significant predictor of mortality (Prohászka et al., 2013). Oliveira et al. studied myocardial biopsies in heart failure before and after implantation of left ventricular assist devices, compared to normal control biopsies obtained from donor hearts (Oliveira et al., 2006). They found that MAC in the myocardium was increased in failing hearts compared to normal controls, however this increase was normalized after left ventricular assist device implantation. Lappegård and Bjørnstad discovered that there was improvement in ejection fraction after cardiac resynchronization therapy, however complement activation was not changed (Lappegård and Bjørnstad, 2006). Bjerre et al. found an increase in sC5b-9 measured in peripheral blood in patients with ischemic origin of the heart failure, but not in the heart failure group as a whole (Bjerre et al., 2010). Gombos et al. demonstrated that high plasma levels of the anaphylatoxin $\mathrm{C} 3 \mathrm{a}$ in patients with left ventricular ejection fraction below $45 \%$ predicted risk for re-hospitalizations, cardiovascular events and mortality (Gombos et al., 2012).

\subsection{Pathogenic role of complement in heart failure development}

C5a-C5a receptor interaction has previously been shown to be centrally involved in sepsis-induced cardiomyocyte dysfunction and heart failure (Niederbichler et al., 2006; Atefi et al., 2011). Recent data show that complement may be a pivotal regulator of sterile inflammatory processes in the heart as well, and lyer et al. showed that C5a receptor antagonism with the cyclic peptide antagonist PMX53 inhibited hypertension-induced myocardial fibrosis and stiffness (lyer et al., 2011). Zhang et al. recently demonstrated complement activation during hypertension and that a $\mathrm{C5a}$ receptor signaling pathway on blood monocytes/macrophages played a pathological role in angiotensin II-induced cardiac inflammation and remodeling (Zhang et al., 2014). Conversely, C5a-receptor deficiency in a murine knock-out model has been associated with decreased resistance to cardiac stress, underscoring that complement might act as a double-edged 
sword also in the heart (Mullick et al., 2011). The mechanisms for in situ increased complement activation in heart failure are currently unknown, but myocardial levels of complement factor B are upregulated after myocardial infarction through toll-like receptor signaling and inflammatory cytokines (Singh et al., 2009; Singh et al., 2012). Complement factor B deficient mice subjected to myocardial infarction have improved survival and cardiac function, less cardiac hypertrophy, and importantly, markedly reduced myocardial C3 deposition. It is conceivable that increased myocardial complement factor B production may represent a mechanism for increased local complement activation that again may promote the pathogenesis of heart failure.

Thus, components of the complement system can be used to assess prognosis in heart failure, and experimental data are emerging that indicate a direct pathogenic role of complement activation. However, to date there are no studies on complement directed therapy in patients with heart failure.

\section{Arrhythmias and the complement system}

It is established that atrial fibrillation is associated with increased inflammatory activity, reviewed in (Lappegård et al., 2013), and also that inflammation is a key player in the development of thrombo-embolic complications (Hijazi et al., 2013). Paradoxically, due to increased survival in coronary heart disease and congestive heart failure, along with an ageing population, the prevalence of atrial fibrillation is increasing.

In a study performed nearly two decades ago, Bruins et al. found that complement activation after CABG was associated with increased CRP-levels and furthermore that this complement activation increased the risk of postsurgery arrhythmia (Bruins et al., 1997). Dernellis and Panaretou found, in a population study from a Greek island, that increased inflammation, as defined by serum levels of CRP, C3 and C4, increased the risk of atrial fibrillation (Dernellis and Panaretou, 2006). However, elevated CRP levels alone did not predict risk of atrial fibrillation whereas the combination of elevated CRP and 
complement levels did. In a larger population based study from Sweden, complement factors C3 and C4 separately failed to predict risk of atrial fibrillation, whereas a combination of inflammation sensitive proteins, including C3 and C4, did (Adamsson Eryd et al., 2011). In a proteomic study of non-valvular atrial fibrillation, an increased level of vitronectin, a terminal pathway inhibitor, was found in patients with hypertension, while an increased level of C5-precursor protein was found in patients with diabetes (Chan et al., 2012). Finally, atrial fibrillation is a known and frequent complication of heart surgery, including CABG and valve surgery (Maisel et al., 2001). Rubens et al. used a copolymer in the bypass-circuit tubes and found a decrease in generation of plasma sC5b-9, and the addition of methylprednisolone further reduced sC5b-9 levels and also the occurrence of atrial fibrillation (Rubens et al., 2005).

There are few studies addressing arrhythmias other than atrial fibrillation, however Di Domenico et al. performed a proteomic study of patients with Brugada syndrome, an inherited disease with increased risk of sudden death due to altered ionic channels in the cardiomyocytes (Di Domenico et al., 2013). They detected increased plasma levels of the complement inhibitors factor $\mathrm{H}$, vitronectin and clusterin, the latter being a terminal pathway inhibitor.

Even if there are relatively few studies on atrial fibrillation and complement, there are clear indications that inflammation in general is important in atrial fibrillation. Some studies underscore the importance of complement in particular, which could open therapeutic possibilities in the future.

\section{Chagas disease and the complement system}

Infectious agents may directly or indirectly cause myocardial failure. Thus, viruses like enterovirus and parvovirus B19 are well known causes of myocarditis. Bacteria like Borrelia species and Chlamydophila pneumoniae may affect the myocardium. In Latin America, Chagas disease causes up to $21 \%$ of the heart failure cases (Bocchi et al., 2013), and here we discuss this as a model for the involvement of complement in infectious-mediated heart 
disease. Chagas disease is caused by the protozoa Trypanasoma cruzi ( $T$ cruzi), is endemic in Latin America, but due to increased intercontinental travel, the disease can be encountered in other parts of the world as well (Nunes et al., 2013). A few of the patients with acute febrile illness due to $T$ cruzi may have fatal acute myocarditis, and up to $30 \%$ of the patients with Chagas disease develop chronic heart disease after 15-30 years, including conduction disturbances, bradyarrhythmias, tachyarrhythmias, apical aneurisms and congestive heart failure (Rassi et al., 2010).

A decade ago Ferreira et al. detected that calreticulin from $T$ cruzi, a multifunctional protein present in many cell types, specifically inhibits complement activation through the classical and the lectin pathway (Ferreira et al., 2004), a finding later confirmed by others (Valck et al., 2010; Ramírez et al., 2011). Sosoniuk et al. recently detected that calreticulin binds directly to ficolin-2, thus inhibiting complement activation through the lectin pathway (Sosoniuk et al., 2014). The lectin pathway has also been shown to attack $T$ cruzi early during infection, and MBL, ficolin-2 and ficolin-3 bind to $T$ cruzi (Cestari et al., 2009). Polymorphisms in the MBL2 gene with subsequent low levels of MBL increase the risk for Chagas disease, hence confirming that the lectin pathway has a protective role (Weitzel et al., 2012). Lower levels of plasma ficolin-2 have been observed in patients with Chagas disease than in controls (Luz et al., 2013). The $T$ cruzi parasites may induce microvesicles from blood cells, and these microvesicles form a complex on the $T$ cruzi surface with the $\mathrm{C} 3$ convertase, the crucial common complement activation step, protecting the $T$ cruzi from complement attack (Cestari et al., 2012).

In an autopsy study, myocardial biopsies from Chagas patients were compared to biopsies from dilated cardiomyopathy of other causes. The Chagas patients had increased expression of MAC in the myocardium, but not of the inhibitor CD59 (Aiello et al., 2002). Regulators of the human complement system are crucial in order to keep the system "in check" and thereby avoid untoward activation and damage. $T$ cruzi produces different types of complement regulatory proteins (Beucher and Norris, 2008). One of these, the complement $\mathrm{C} 2$ receptor inhibitor trispanning (CRIT) protein inhibits 
$\mathrm{C} 2$ and thereby the classical and lectin pathways. Parasites with overexpression of the CRIT gene have higher survival in human serum (Cestari et al., 2008). Later it has been demonstrated that CRIT inhibits MASP-2 cleavage of $\mathrm{C} 2$, thus inhibiting the formation of the C3 convertase (Cestari et al., 2009).

Clearly, the complement system is important in Chagas disease, even though the exact mechanism explaining how the complement system is involved in heart disease is unknown. This infection is a considerable contributor to heart failure, especially in Latin America. Both the parasite and the host utilize components of the complement system, which therefore might be an attractive target for medical therapy in the future, and future research should address this.

\section{Conclusions and directions for future research}

In heart diseases the importance of the innate immune system in general, and the complement system in particular, has achieved increasing recognition. So far, the results from trials with complement inhibition in patients with coronary heart disease have been disappointing. However, research should continue to reveal more of the mechanisms by which the complement system contributes to heart disease. The development of new complement inhibitors is promising, and specific approaches like tissue targeted therapy and inhibition of specific proteins and receptors are to be explored. Furthermore, the question of appropriate timing of complement inhibition in the various clinical settings should be subject to more research. We have previously discussed the concept of dual inhibition of "bottle neck" molecules of innate immunity, e.g. C3 or C5 and Toll-like receptor co-factor CD14, in inflammatory diseases (Mollnes et al., 2008; Barratt-Due et al., 2012), and future research should explore new possibilities for inhibition and modulation of the innate immune system in order to further reduce the burden of heart diseases. 


\section{References}

Adamsson Eryd, S., Smith, J.G., Melander, O., Hedblad, B., Engström, G., 2011. Inflammation-sensitive proteins and risk of atrial fibrillation: a population-based cohort study. European journal of epidemiology 26, 449455.

Aiello, V.D., Reis, M.M., Benvenuti, L.A., Higuchi, M.d.L., Ramires, J.A., Halperin, J.A., 2002. A possible role for complement in the pathogenesis of chronic chagasic cardiomyopathy. J Pathol 197, 224-229.

Alipour, A., Cabezas, M.C., Elte, J.W., Vallvé, J.C., Ribalta, J., Zwinderman, A.H., Defesche, J.C., Jukema, J.W., 2011. Mannose binding lectin 2 haplotypes do not affect the progression of coronary atherosclerosis in men with proven coronary artery disease treated with pravastatin. Atherosclerosis $215,125-129$.

APEX AMI Investigators, 2007. Pexelizumab for acute ST-elevation myocardial infarction in patients undergoing primary percutaneous coronary intervention. Journal of the American Medical Association 297, 43-51.

Atefi, G., Zetoune, F.S., Herron, T.J., Jalife, J., Bosmann, M., Al-Aref, R., Sarma, J.V., Ward, P.A., 2011. Complement dependency of cardiomyocyte release of mediators during sepsis. The Federation of American Societies for Experimental Biology journal 25, 2500-2508.

Aukrust, P., Gullestad, L., Lappegard, K.T., Ueland, T., Aass, H., Wikeby, L., Simonsen, S., Froland, S.S., Mollnes, T.E., 2001. Complement Activation in Patients With Congestive Heart Failure: Effect of High-Dose Intravenous Immunoglobulin Treatment. Circulation 104, 1494-1500.

Banz, Y., Rieben, R., 2012. Role of complement and perspectives for intervention in ischemia-reperfusion damage. Annals of medicine 44, 205-217. 
Barratt-Due, A., Pischke, S.E., Brekke, O.L., Thorgersen, E.B., Nielsen, E.W., Espevik, T., Huber-Lang, M., Mollnes, T.E., 2012. Bride and groom in systemic inflammation--the bells ring for complement and Toll in cooperation. Immunobiology 217, 1047-1056.

Beucher, M., Norris, K.A., 2008. Sequence diversity of the Trypanosoma cruzi complement regulatory protein family. Infection and immunity 76, 750-758.

Bjerre, M., Kistorp, C., Hansen, T.K., Faber, J., Lip, G.Y., Hildebrandt, P., Flyvbjerg, A., 2010. Complement activation, endothelial dysfunction, insulin resistance and chronic heart failure. Scandinavian cardiovascular journal 44 , 260-266.

Blaskó, B., Kolka, R., Thorbjornsdottir, P., Sigurdarson, S.T., Sigurdsson, G., Rónai, Z., Sasvári-Székely, M., Bödvarsson, S., Thorgeirsson, G., Prohászka, Z., Kovács, M., Füst, G., Arason, G.J., 2008. Low complement C4B gene copy number predicts short-term mortality after acute myocardial infarction. Int Immunol 20, 31-37.

Bocchi, E.A., Arias, A., Verdejo, H., Diez, M., Gómez, E., Castro, P., Interamerican Society of Cardiology, 2013. The reality of heart failure in Latin America. Journal of the American College of Cardiology 62, 949-958.

Bruins, P., te Velthuis, H., Yazdanbakhsh, A.P., Jansen, P.G., van Hardevelt, F.W., de Beaumont, E.M., Wildevuur, C.R., Eijsman, L., Trouwborst, A., Hack, C.E., 1997. Activation of the complement system during and after cardiopulmonary bypass surgery: postsurgery activation involves C-reactive protein and is associated with postoperative arrhythmia. Circulation 96, 35423548.

Busche, M.N., Pavlov, V., Takahashi, K., Stahl, G.L., 2009. Myocardial ischemia and reperfusion injury is dependent on both IgM and mannose- 
binding lectin. American journal of physiology. Heart and circulatory physiology 297, H1853-H1859.

Cestari, I., Ansa-Addo, E., Deolindo, P., Inal, J.M., Ramirez, M.I., 2012. Trypanosoma cruzi immune evasion mediated by host cell-derived microvesicles. Journal of immunology 188, 1942-1952.

Cestari, I., Evans-Osses, I., Freitas, J.C., Inal, J.M., Ramirez, M.I., 2008. Complement $\mathrm{C} 2$ receptor inhibitor trispanning confers an increased ability to resist complement-mediated lysis in Trypanosoma cruzi. The Journal of infectious diseases 198, 1276-1283.

Cestari, I., Krarup, A., Sim, R.B., Inal, J.M., Ramirez, M.I., 2009. Role of early lectin pathway activation in the complement-mediated killing of Trypanosoma cruzi. Molecular immunology 47, 426-437.

Chan, M.Y., Lin, M., Lucas, J., Moseley, A., Thompson, J.W., Cyr, D., Ueda, H., Kajikawa, M., Ortel, T.L., Becker, R.C., 2012. Plasma proteomics of patients with non-valvular atrial fibrillation on chronic anti-coagulation with warfarin or a direct factor Xa inhibitor. Thrombosis and haemostasis 108, 1180-1191.

Chugh, S.S., Havmoeller, R., Narayanan, K., Singh, D., Rienstra, M., Benjamin, E.J., Gillum, R.F., Kim, Y.H., McAnulty, J.H., Zheng, Z.J., Forouzanfar, M.H., Naghavi, M., Mensah, G.A., Ezzati, M., Murray, C.J., 2014. Worldwide epidemiology of atrial fibrillation: a global burden of disease 2010 study. Circulation 129, 837-847.

Cook, C., Cole, G., Asaria, P., Jabbour, R., Francis, D.P., 2014. The annual global economic burden of heart failure. International journal of cardiology 171, 368-376.

Cubedo, J., Padró, T., Badimon, L., 2013. Coordinated proteomic signature changes in immune response and complement proteins in acute myocardial 
infarction: the implication of serum amyloid P-component. International journal of cardiology $168,5196-5204$.

del Balzo, U.H., Levi, R., Polley, M.J., 1985. Cardiac dysfunction caused by purified human $\mathrm{C} 3 \mathrm{a}$ anaphylatoxin. Proceedings of the National Academy of Sciences of the United States of America 82, 886-890.

Dernellis, J., Panaretou, M., 2006. Effects of C-reactive protein and the third and fourth components of complement ( $\mathrm{C} 3$ and $\mathrm{C} 4$ ) on incidence of atrial fibrillation. The American journal of cardiology 97, 245-248.

Di Domeinco M.,Scumaci D., Grasso S., Gaspari M., Curcio A., Oliva A., Ausania F., Di Nunzio C., Ricciardi C., Santini A.C., Rizzo F.A., Romano Carratelli C., Lamberti M., Conti D., La Montagna R., Tomei V., Malafoglia V., Pascali V.L, Ricci P, Indolfi C, Costanzo F, Cuda G., 2013. Biomarker discovery by plasma proteomics in familial Brugada Syndrome. Frontiers in Biosciences (Landmark Edition) 18, 564-571.

Distelmaier, K., Adlbrecht, C., Jakowitsch, J., Winkler, S., Dunkler, D., Gerner, C., Wagner, O., Lang, I.M., Kubicek, M., 2009. Local complement activation triggers neutrophil recruitment to the site of thrombus formation in acute myocardial infarction. Thrombosis and haemostasis 102, 564-572.

Duewell, P., Kono, H., Rayner, K.J., Sirois, C.M., Vladimer, G., Bauernfeind, F.G., Abela, G.S., Franchi, L., Nuñez, G., Schnurr, M., Espevik, T., Lien, E., Fitzgerald, K.A., Rock, K.L., Moore, K.J., Wright, S.D., Hornung, V., Latz, E., 2010. NLRP3 inflammasomes are required for atherogenesis and activated by cholesterol crystals. Nature 464, 1357-1361.

Edmunds, L.H., 1998. Inflammatory response to cardiopulmonary bypass. The Annals of thoracic surgery 66, S12-6; discussion S25-8.

Engelmann, B., Massberg, S., 2013. Thrombosis as an intravascular effector of innate immunity. Nature Reviews Immunology 13, 34-45. 
Engström, G., Hedblad, B., Janzon, L., Lindgärde, F., 2007. Complement C3 and $\mathrm{C} 4$ in plasma and incidence of myocardial infarction and stroke: a population-based cohort study. Eur J Cardiovasc Prev Rehabil 14, 392-397.

Fairweather, D., Frisancho-Kiss, S., Njoku, D.B., Nyland, J.F., Kaya, Z., Yusung, S.A., Davis, S.E., Frisancho, J.A., Barrett, M.A., Rose, N.R., 2006. Complement receptor 1 and 2 deficiency increases coxsackievirus B3induced myocarditis, dilated cardiomyopathy, and heart failure by increasing macrophages, IL-1beta, and immune complex deposition in the heart. Journal of immunology 176, 3516-3524.

Ferreira, V., Valck, C., Sánchez, G., Gingras, A., Tzima, S., Molina, M.C., Sim, R., Schwaeble, W., Ferreira, A., 2004. The classical activation pathway of the human complement system is specifically inhibited by calreticulin from Trypanosoma cruzi. Journal of immunology 172, 3042-3050.

Frangogiannis, N.G., 2014. The immune system and the remodeling infarcted heart: cell biological insights and therapeutic opportunities. Journal of cardiovascular pharmacology 63, 185-195.

Frauenknecht, V., Thiel, S., Storm, L., Meier, N., Arnold, M., Schmid, J.P., Saner, H., Schroeder, V., 2013. Plasma levels of mannan-binding lectin (MBL)-associated serine proteases (MASPs) and MBL-associated protein in cardio- and cerebrovascular diseases. Clinical and experimental immunology $173,112-120$.

Gehrs, K.M., Jackson, J.R., Brown, E.N., Allikmets, R., Hageman, G.S., 2010. Complement, age-related macular degeneration and a vision of the future. Archives of ophthalmology 128, 349-358.

Gerczuk, P.Z., Kloner, R.A., 2012. An update on cardioprotection: a review of the latest adjunctive therapies to limit myocardial infarction size in clinical trials. Journal of the American College of Cardiology 59, 969-978. 
Gombos, T., Förhécz, Z., Pozsonyi, Z., Széplaki, G., Kunde, J., Füst, G., Jánoskuti, L., Karádi, I., Prohászka, Z., 2012. Complement anaphylatoxin C3a as a novel independent prognostic marker in heart failure. Clinical research in cardiology : official journal of the German Cardiac Society 101, 607-615.

Gorsuch, W.B., Chrysanthou, E., Schwaeble, W.J., Stahl, G.L., 2012. The complement system in ischemia-reperfusion injuries. Immunobiology 217, 1026-1033.

Granger, C.B., Mahaffey, K.W., Weaver, W.D., Theroux, P., Hochman, J.S., Filloon, T.G., Rollins, S., Todaro, T.G., Nicolau, J.C., Ruzyllo, W., Armstrong, P.W., COMMA Investigators, 2003. Pexelizumab, an anti-C5 complement antibody, as adjunctive therapy to primary percutaneous coronary intervention in acute myocardial infarction: the COMplement inhibition in Myocardial infarction treated with Angioplasty (COMMA) trial. Circulation 108, 1184-1190.

Hansson, G.K., Hermansson, A., 2011. The immune system in atherosclerosis. Nature immunology 12, 204-212.

Hansson, G.K., Libby, P., 2006. The immune response in atherosclerosis: a double-edged sword. Nature Reviews Immunology 6, 508-519.

Haskard, D.O., Boyle, J.J., Mason, J.C., 2008. The role of complement in atherosclerosis. Current opinion in lipidology 19, 478-482.

Haverich, A., Shernan, S.K., Levy, J.H., Chen, J.C., Carrier, M., Taylor, K.M., Van de Werf, F., Newman, M.F., Adams, P.X., Todaro, T.G., van der Laan, M., Verrier, E.D., 2006. Pexelizumab reduces death and myocardial infarction in higher risk cardiac surgical patients. The Annals of thoracic surgery 82 , 486-492.

Heusch, G., 2013. Cardioprotection: chances and challenges of its translation to the clinic. The Lancet 381, 166-175. 
Hijazi, Z., Oldgren, J., Siegbahn, A., Granger, C.B., Wallentin, L., 2013. Biomarkers in atrial fibrillation: a clinical review. European heart journal . Hill, J.H., Ward, P.A., 1971. The phlogistic role of C3 leukotactic fragments in myocardial infarcts of rats. The Journal of experimental medicine $133,885-$ 900.

Hoffmeister, H.M., Ehlers, R., Büttcher, E., Kazmaier, S., Szabo, S., Beyer, M.E., Steinmetz, A., Seipel, L., 2002. Comparison of C-reactive protein and terminal complement complex in patients with unstable angina pectoris versus stable angina pectoris. The American journal of cardiology 89, 909-912.

Holt, C.B., Thiel, S., Munk, K., Ostergaard, J.A., Bøtker, H.E., Hansen, T.K., 2014. Association between endogenous complement inhibitor and myocardial salvage in patients with myocardial infarction. European heart journal. Acute cardiovascular care 3, 3-9.

Horváth, Z., Csuka, D., Vargova, K., Kovács, A., Molnár, A.A., GulácsiBárdos, P., Leé, S., Varga, L., Kiss, R.G., Préda, I., Füst, G., 2012. Elevated $\mathrm{C} 1 \mathrm{rC} 1 \mathrm{sC} 1 \mathrm{inh}$ levels independently predict atherosclerotic coronary heart disease. Molecular immunology 54, 8-13.

Huber-Lang, M., Sarma, J.V., Zetoune, F.S., Rittirsch, D., Neff T.A., McGuire, S.R., Lambris, J.D., Warner, R.L., Flierl, M.A., Hoesel, L.M., Gebhard, F., Younger, J.G., Drouin, S.M., Wetsel, R.A., Ward, P.A., 2006. Generation of $\mathrm{C} 5 \mathrm{a}$ in the absence of $\mathrm{C} 3$ : a new complement activation pathway. Nature Med, $12,682-687$.

Iyer, A., Woodruff, T.M., Wu, M.C., Stylianou, C., Reid, R.C., Fairlie, D.P., Taylor, S.M., Brown, L., 2011. Inhibition of inflammation and fibrosis by a complement $\mathrm{C} 5 \mathrm{a}$ receptor antagonist in DOCA-salt hypertensive rats. Journal of cardiovascular pharmacology 58, 479-486. 
Jennings, R.B., 2013. Historical perspective on the pathology of myocardial ischemia/reperfusion injury. Circulation research 113, 428-438.

Jordan, J.E., Montalto, M.C., Stahl, G.L., 2001. Inhibition of Mannose-Binding Lectin Reduces Postischemic Myocardial Reperfusion Injury. Circulation 104, 1413-1418.

Kardys, I., Klaver, C.C., Despriet, D.D., Bergen, A.A., Uitterlinden, A.G., Hofman, A., Oostra, B.A., Van Duijn, C.M., de Jong, P.T., Witteman, J.C., 2006. A common polymorphism in the complement factor $\mathrm{H}$ gene is associated with increased risk of myocardial infarction: the Rotterdam Study. Journal of the American College of Cardiology 47, 1568-1575.

Kishida, K., Nakagawa, Y., Kobayashi, H., Mazaki, T., Yokoi, H., Yanagi, K., Funahashi, T., Shimomura, I., 2014. High serum C1q-binding adiponectin levels in male patients with acute coronary syndrome. Cardiovascular diabetology 13,9 .

Kloner, R.A., 2013. Current state of clinical translation of cardioprotective agents for acute myocardial infarction. Circulation research 113, 451-463.

Lappegård, K.T., Bjørnstad, H., 2006. Anti-inflammatory effect of cardiac resynchronization therapy. Pacing and clinical electrophysiology 29, 753-758.

Lappegård, K.T., Hovland, A., Pop, G.A., Mollnes, T.E., 2013. Atrial fibrillation: inflammation in disguise? Scandinavian journal of immunology 78, 112-119.

Lazar, H.L., Bokesch, P.M., van Lenta, F., Fitzgerald, C., Emmett, C., Marsh, H.C., Ryan, U., OBE and the TP10 Cardiac Surgery Study Group, 2004. Soluble human complement receptor 1 limits ischemic damage in cardiac surgery patients at high risk requiring cardiopulmonary bypass. Circulation 110, II274-II279. 
Lazar, H.L., Keilani, T., Fitzgerald, C.A., Shapira, O.M., Hunter, C.T., Shemin, R.J., Marsh, H.C., Ryan, U.S., TP10 Cardiac Surgery Study Group, 2007. Beneficial effects of complement inhibition with soluble complement receptor 1 (TP10) during cardiac surgery: is there a gender difference? Circulation 116, 183-188.

Leban, N., Jraba, K., Chalghoum, A., Hassine, S., Elhayek, D., Denden, S., Lakhdhar, R., Maatoug, F., Gamra, H., Braham, H., Chibani, J.B., Khelil, A.H., 2013. Polymorphism of C3 complement in association with myocardial infarction in a sample of central Tunisia. Diagnostic pathology 8, 93.

Lindberg, S., Pedersen, S.H., Mogelvang, R., Galatius, S., Flyvbjerg, A., Jensen, J.S., Bjerre, M., 2012. Soluble form of membrane attack complex independently predicts mortality and cardiovascular events in patients with ST-elevation myocardial infarction treated with primary percutaneous coronary intervention. American heart journal 164, 786-792.

Luz, P.R., Boldt, A.B., Grisbach, C., Kun, J.F., Velavan, T.P., MessiasReason, I.J., 2013. Association of L-ficolin levels and FCN2 genotypes with chronic Chagas disease. PloS one 8,e60237.

Mahaffey, K.W., Granger, C.B., Nicolau, J.C., Ruzyllo, W., Weaver, W.D., Theroux, P., Hochman, J.S., Filloon, T.G., Mojcik, C.F., Todaro, T.G., Armstrong, P.W., COMPLY Investigators, 2003. Effect of pexelizumab, an anti-C5 complement antibody, as adjunctive therapy to fibrinolysis in acute myocardial infarction: the COMPlement inhibition in myocardial infarction treated with thromboLYtics (COMPLY) trial. Circulation 108, 1176-1183.

Maisel, W.H., Rawn, J.D., Stevenson, W.G., 2001. Atrial fibrillation after cardiac surgery. Annals of internal medicine 135, 1061-1073.

Martel, C., Granger, C.B., Ghitescu, M., Stebbins, A., Fortier, A., Armstrong, P.W., Bonnefoy, A., Theroux, P., 2012. Pexelizumab fails to inhibit assembly of the terminal complement complex in patients with ST-elevation myocardial 
infarction undergoing primary percutaneous coronary intervention. Insight from a substudy of the Assessment of Pexelizumab in Acute Myocardial Infarction (APEX-AMI) trial. American heart journal 164, 43-51.

Mellbin, L.G., Bjerre, M., Thiel, S., Hansen, T.K., 2012. Complement activation and prognosis in patients with type 2 diabetes and myocardial infarction: a report from the DIGAMI 2 trial. Diabetes care 35, 911-917.

Mollnes, T.E., Andreassen, I.H., Høgåsen, K., Hack, C.E., Harboe, M., 1997. Effect of whole and fractionated intravenous immunoglobulin on complement in vitro. Molecular immunology 34, 719-729.

Mollnes, T.E., Christiansen, D., Brekke, E.O.L., Espevik, T., 2008. Hypothesis: combined inhibition of complement and CD14 as treatment regimen to attenuate the inflammatory response. Advances in experimental medicine and biology 632, 253-263.

Moran, A.E., Forouzanfar, M.H., Roth, G., Mensah, G., Ezzati, M., Murray, C.J., Naghavi, M., 2014a. Temporal Trends in Ischemic Heart Disease Mortality in 21 World Regions, 1980-2010: The Global Burden of Disease 2010 Study. Circulation 129, 1483-1492.

Moran, A.E., Forouzanfar, M.H., Roth, G., Mensah, G.A., Ezzati, M., Flaxman, A., Murray, C.J., Naghavi, M., 2014b. The Global Burden of Ischemic Heart Disease in 1990 and 2010: The Global Burden of Disease 2010 Study. Circulation 129, 1493-1501.

Mueller, M., Herzog, C., Larmann, J., Schmitz, M., Hilfiker-Kleiner, D., Gessner, J.E., Theilmeier, G., 2013. The receptor for activated complement factor 5 (C5aR) conveys myocardial ischemic damage by mediating neutrophil transmigration. Immunobiology 218, 1131-1138.

Mullick, A., Tremblay, J., Leon, Z., Gros, P., 2011. A novel role for the fifth component of complement (C5) in cardiac physiology. PloS one 6,e22919. 
Nicaud, V., Francomme, C., Ruidavets, J.B., Luc, G., Arveiler, D., Kee, F., Evans, A., Morrison, C., Blankenberg, S., Cambien, F., Tiret, L., 2007. Lack of association between complement factor $\mathrm{H}$ polymorphisms and coronary artery disease or myocardial infarction. Journal of molecular medicine 85, 771-775.

Niederbichler, A.D., Hoesel, L.M., Westfall, M.V., Gao, H., Ipaktchi, K.R., Sun, L., Zetoune, F.S., Su, G.L., Arbabi, S., Sarma, J.V., Wang, S.C., Hemmila, M.R., Ward, P.A., 2006. An essential role for complement C5a in the pathogenesis of septic cardiac dysfunction. The Journal of experimental medicine 203, 53-61.

Nilsson, B., Hamad, O.A., Ahlström, H., Kullberg, J., Johansson, L., Lindhagen, L., Haenni, A., Ekdahl, K.N., Lind, L., 2014. C3 And C4 Are Strongly Related To Adipose Tissue Variables And Cardiovascular Risk Factors. European journal of clinical investigation, electronically published ahead of print 22 April 2014.

Nunes, M.C., Dones, W., Morillo, C.A., Encina, J.J., Ribeiro, A.L., Council on Chagas Disease of the Interamerican Society of Cardiology, 2013. Chagas disease: an overview of clinical and epidemiological aspects. Journal of the American College of Cardiology 62, 767-776.

Oksjoki, R., Laine, P., Helske, S., Vehmaan-Kreula, P., Mäyränpää, M.I., Gasque, P., Kovanen, P.T., Pentikäinen, M.O., 2007. Receptors for the anaphylatoxins $\mathrm{C} 3 \mathrm{a}$ and $\mathrm{C} 5 \mathrm{a}$ are expressed in human atherosclerotic coronary plaques. Atherosclerosis 195, 90-99.

Oliveira, G.H., Brann, C.N., Becker, K., Thohan, V., Koerner, M.M., Loebe, M., Noon, G.P., Torre-Amione, G., 2006. Dynamic expression of the membrane attack complex (MAC) of the complement system in failing human myocardium. The American journal of cardiology 97, 1626-1629. 
Ovize, M., Thibault, H., Przyklenk, K., 2013. Myocardial conditioning: opportunities for clinical translation. Circulation research 113, 439-450.

Palikhe, A., Sinisalo, J., Seppänen, M., Haario, H., Meri, S., Valtonen, V., Nieminen, M.S., Lokki, M.L., 2007. Serum complement C3/C4 ratio, a novel marker for recurrent cardiovascular events. The American journal of cardiology 99, 890-895.

Prohászka, Z., Munthe-Fog, L., Ueland, T., Gombos, T., Yndestad, A., Förhécz, Z., Skjoedt, M.O., Pozsonyi, Z., Gustavsen, A., Jánoskuti, L., Karádi, I., Gullestad, L., Dahl, C.P., Askevold, E.T., Füst, G., Aukrust, P., Mollnes, T.E., Garred, P., 2013. Association of ficolin-3 with severity and outcome of chronic heart failure. PloS one 8, e60976.

Ramírez, G., Valck, C., Molina, M.C., Ribeiro, C.H., López, N., Sánchez, G., Ferreira, V.P., Billetta, R., Aguilar, L., Maldonado, I., Cattán, P., Schwaeble, W., Ferreira, A., 2011. Trypanosoma cruzi calreticulin: a novel virulence factor that binds complement $\mathrm{C} 1$ on the parasite surface and promotes infectivity. Immunobiology 216, 265-273.

Rassi, A., Rassi, A., Marin-Neto, J.A., 2010. Chagas disease. Lancet 375, 1388-1402.

Ricklin, D., Hajishengallis, G., Yang, K., Lambris, J.D., 2010. Complement: a key system for immune surveillance and homeostasis. Nature immunology 11 , 785-797.

Rubens, F.D., Nathan, H., Labow, R., Williams, K.S., Wozny, D., Karsh, J., Ruel, M., Mesana, T., 2005. Effects of methylprednisolone and a biocompatible copolymer circuit on blood activation during cardiopulmonary bypass. The Annals of thoracic surgery 79, 655-665.

Samstad, E.O., Niyonzima, N., Nymo, S., Aune, M.H., Ryan, L., Bakke, S.S., Lappegård, K.T., Brekke, O.L., Lambris, J.D., Damås, J.K., Latz, E., Mollnes, 
T.E., Espevik, T., 2014. Cholesterol crystals induce complement-dependent inflammasome activation and cytokine release. Journal of immunology 192, 2837-2845.

Schoos, M.M., Munthe-Fog, L., Skjoedt, M.O., Ripa, R.S., Lønborg, J., Kastrup, J., Kelbæk, H., Clemmensen, P., Garred, P., 2013. Association between lectin complement pathway initiators, C-reactive protein and left ventricular remodeling in myocardial infarction-a magnetic resonance study. Molecular immunology 54, 408-414.

Shandelya, S.M., Kuppusamy, P., Herskowitz, A., Weisfeldt, M.L., Zweier, J.L., 1993. Soluble complement receptor type 1 inhibits the complement pathway and prevents contractile failure in the postischemic heart. Evidence that complement activation is required for neutrophil-mediated reperfusion injury. Circulation 88, 2812-2826.

Sheedy, F.J., Grebe, A., Rayner, K.J., Kalantari, P., Ramkhelawon, B., Carpenter, S.B., Becker, C.E., Ediriweera, H.N., Mullick, A.E., Golenbock, D.T., Stuart, L.M., Latz, E., Fitzgerald, K.A., Moore, K.J., 2013. CD36 coordinates NLRP3 inflammasome activation by facilitating intracellular nucleation of soluble ligands into particulate ligands in sterile inflammation. Nature immunology 14, 812-820.

Shernan, S.K., Fitch, J.C., Nussmeier, N.A., Chen, J.C., Rollins, S.A., Mojcik, C.F., Malloy, K.J., Todaro, T.G., Filloon, T., Boyce, S.W., Gangahar, D.M., Goldberg, M., Saidman, L.J., Mangano, D.T., Pexelizumab Study Investigators, 2004. Impact of pexelizumab, an anti-C5 complement antibody, on total mortality and adverse cardiovascular outcomes in cardiac surgical patients undergoing cardiopulmonary bypass. The Annals of thoracic surgery 77, 942-950.

Siezenga, M.A., Shaw, P.K., Daha, M.R., Rabelink, T.J., Berger, S.P., 2011. Low Mannose-Binding Lectin (MBL) genotype is associated with future 
cardiovascular events in type 2 diabetic South Asians. A prospective cohort study. Cardiovascular diabetology 10, 60.

Singh, M.V., Kapoun, A., Higgins, L., Kutschke, W., Thurman, J.M., Zhang, R., Singh, M., Yang, J., Guan, X., Lowe, J.S., Weiss, R.M., Zimmermann, K., Yull, F.E., Blackwell, T.S., Mohler, P.J., Anderson, M.E., 2009. $\mathrm{Ca2+/calmodulin-dependent} \mathrm{kinase} \mathrm{II} \mathrm{triggers} \mathrm{cell} \mathrm{membrane} \mathrm{injury} \mathrm{by}$ inducing complement factor $B$ gene expression in the mouse heart. The Journal of clinical investigation 119, 986-996.

Singh, M.V., Swaminathan, P.D., Luczak, E.D., Kutschke, W., Weiss, R.M., Anderson, M.E., 2012. MyD88 mediated inflammatory signaling leads to CaMKII oxidation, cardiac hypertrophy and death after myocardial infarction. $\mathrm{J}$ Mol Cell Cardiol 52, 1135-1144.

Smith, P.K., Shernan, S.K., Chen, J.C., Carrier, M., Verrier, E.D., Adams, P.X., Todaro, T.G., Muhlbaier, L.H., Levy, J.H., PRIMO-CABG II Investigators, 2011. Effects of $C 5$ complement inhibitor pexelizumab on outcome in high-risk coronary artery bypass grafting: combined results from the PRIMO-CABG I and II trials. The Journal of thoracic and cardiovascular surgery 142, 89-98.

Sofat, R., Casas, J.P., Kumari, M., Talmud, P.J., Ireland, H., Kivimaki, M., Marmot, M., Hughes, A.D., Thom, S., Ebrahim, S., Whittaker, J.C., Smeeth, L., Lawlor, D.A., Humphries, S.E., Hingorani, A.D., 2010. Genetic variation in complement factor $\mathrm{H}$ and risk of coronary heart disease: eight new studies and a meta-analysis of around 48,000 individuals. Atherosclerosis $213,184-$ 190.

Sosoniuk, E., Vallejos, G., Kenawy, H., Gaboriaud, C., Thielens, N., Fujita, T., Schwaeble, W., Ferreira, A., Valck, C., 2014. Trypanosoma cruzi calreticulin inhibits the complement lectin pathway activation by direct interaction with LFicolin. Molecular immunology 60, 80-85. 
Speidl, W.S., Exner, M., Amighi, J., Kastl, S.P., Zorn, G., Maurer, G., Wagner, O., Huber, K., Minar, E., Wojta, J., Schillinger, M., 2005. Complement component $\mathrm{C} 5 \mathrm{a}$ predicts future cardiovascular events in patients with advanced atherosclerosis. European heart journal 26, 2294-2299.

Stark, K., Neureuther, K., Sedlacek, K., Hengstenberg, W., Fischer, M., Baessler, A., Wiedmann, S., Jeron, A., Holmer, S., Erdmann, J., Schunkert, $\mathrm{H}$., Hengstenberg, C., 2007. The common $\mathrm{Y} 402 \mathrm{H}$ variant in complement factor $\mathrm{H}$ gene is not associated with susceptibility to myocardial infarction and its related risk factors. Clinical science 113, 213-218.

Széplaki, G., Prohászka, Z., Duba, J., Rugonfalvi-Kiss, S., Karádi, I., Kókai, M., Kramer, J., Füst, G., Kleiber, M., Romics, L., Varga, L., 2004. Association of high serum concentration of the third component of complement (C3) with pre-existing severe coronary artery disease and new vascular events in women. Atherosclerosis 177, 383-389.

Testa, L., Van Gaal, W.J., Bhindi, R., Biondi-Zoccai, G.G., Abbate, A., Agostoni, P., Porto, I., Andreotti, F., Crea, F., Banning, A.P., 2008. Pexelizumab in ischemic heart disease: a systematic review and metaanalysis on 15,196 patients. The Journal of thoracic and cardiovascular surgery $136,884-893$.

Thomas, T.C., Rollins, S.A., Rother, R.P., Giannoni, M.A., Hartman, S.L., Elliott, E.A., Nye, S.H., Matis, L.A., Squinto, S.P., Evans, M.J., 1996. Inhibition of complement activity by humanized anti-C5 antibody and single-chain Fv. Molecular immunology 33, 1389-1401.

Timmers, L., Pasterkamp, G., de Hoog, V.C., Arslan, F., Appelman, Y., de Kleijn, D.P., 2012. The innate immune response in reperfused myocardium. Cardiovascular research 94, 276-283.

Torzewski, M., Bhakdi, S., 2013. Complement and atherosclerosis-united to the point of no return? Clinical biochemistry 46, 20-25. 
Trendelenburg, M., Theroux, P., Stebbins, A., Granger, C., Armstrong, P., Pfisterer, M., 2010. Influence of functional deficiency of complement mannose-binding lectin on outcome of patients with acute ST-elevation myocardial infarction undergoing primary percutaneous coronary intervention. European heart journal 31, 1181-1187.

Valck, C., Ramírez, G., López, N., Ribeiro, C.H., Maldonado, I., Sánchez, G., Ferreira, V.P., Schwaeble, W., Ferreira, A., 2010. Molecular mechanisms involved in the inactivation of the first component of human complement by Trypanosoma cruzi calreticulin. Molecular immunology 47, 1516-1521.

van der Pals, J., Koul, S., Andersson, P., Götberg, M., Ubachs, J.F., Kanski, M., Arheden, H., Olivecrona, G.K., Larsson, B., Erlinge, D., 2010. Treatment with the C5a receptor antagonist ADC-1004 reduces myocardial infarction in a porcine ischemia-reperfusion model. BMC cardiovascular disorders 10, 45.

Vengen, I.T., Madsen, H.O., Garred, P., Platou, C., Vatten, L., Videm, V., 2012. Mannose-Binding Lectin Deficiency Is Associated with Myocardial Infarction: The HUNT2 Study in Norway. PloS one 7, e42113.

Verrier, E.D., Shernan, S.K., Taylor, K.M., Van de Werf, F., Newman, M.F., Chen, J.C., Carrier, M., Haverich, A., Malloy, K.J., Adams, P.X., Todaro, T.G., Mojcik, C.F., Rollins, S.A., Levy, J.H., PRIMO-CABG Investigators, 2004. Terminal complement blockade with pexelizumab during coronary artery bypass graft surgery requiring cardiopulmonary bypass: a randomized trial. Journal of the American Medical Association 291, 2319-2327.

Walsh, M.C., Bourcier, T., Takahashi, K., Shi, L., Busche, M.N., Rother, R.P., Solomon, S.D., Ezekowitz, R.A., Stahl, G.L., 2005. Mannose-binding lectin is a regulator of inflammation that accompanies myocardial ischemia and reperfusion injury. Journal of immunology 175, 541-546. 
Weber, C., Noels, H., 2011. Atherosclerosis: current pathogenesis and therapeutic options. Nature medicine 17, 1410-1422.

Weisman, H.F., Bartow, T., Leppo, M.K., Marsh, H.C., Carson, G.R., Concino, M.F., Boyle, M.P., Roux, K.H., Weisfeldt, M.L., Fearon, D.T., 1990. Soluble human complement receptor type 1: in vivo inhibitor of complement suppressing post-ischemic myocardial inflammation and necrosis. Science 249, 146-151.

Weitzel, T., Zulantay, I., Danquah, I., Hamann, L., Schumann, R.R., Apt, W., Mockenhaupt, F.P., 2012. Mannose-binding lectin and Toll-like receptor polymorphisms and Chagas disease in Chile. The American journal of tropical medicine and hygiene 86, 229-232.

Yndestad, A., Damås, J.K., Øie, E., Ueland, T., Gullestad, L., Aukrust, P., 2007. Role of inflammation in the progression of heart failure. Current cardiology reports 9, 236-241.

Zee, R.Y., Diehl, K.A., Ridker, P.M., 2006. Complement factor H Y402H gene polymorphism, C-reactive protein, and risk of incident myocardial infarction, ischaemic stroke, and venous thromboembolism: a nested case-control study. Atherosclerosis 187, 332-335.

Zhang, C., Li, Y., Wang, C., Wu, Y., Cui, W., Miwa, T., Sato, S., Li, H., Song, W.C., Du, J., 2014. Complement 5a Receptor Mediates Angiotensin IIInduced Cardiac Inflammation and Remodeling. Arteriosclerosis, thrombosis, and vascular biology, electronically published ahead of print 17 April 2014.

Zhang, M., Hou, Y.J., Cavusoglu, E., Lee, D.C., Steffensen, R., Yang, L., Bashari, D., Villamil, J., Moussa, M., Fernaine, G., Jensenius, J.C., Marmur, J.D., Ko, W., Shevde, K., 2013. MASP-2 activation is involved in ischemiarelated necrotic myocardial injury in humans. International journal of cardiology 166, 499-504. 
Øhlenschlaeger, T., Garred, P., Madsen, H.O., Jacobsen, S., 2004. Mannosebinding lectin variant alleles and the risk of arterial thrombosis in systemic lupus erythematosus. The New England journal of medicine 351, 260-267.

Ørn, S., Manhenke, C., Ueland, T., Damås, J.K., Mollnes, T.E., Edvardsen, T., Aukrust, P., Dickstein, K., 2009. C-reactive protein, infarct size, microvascular obstruction, and left-ventricular remodelling following acute myocardial infarction. European heart journal 30, 1180-1186. 
Table 1. Pexelizumab vs. placebo in coronary heart disease.

\begin{tabular}{|c|c|c|c|c|}
\hline Reference & Clinical setting & $\mathrm{N}$ & Primary endpoint & P-value \\
\hline Mahaffey et al., 2003 & STEMI ${ }^{1}$, fibrinolysis & 920 & Infarct size & 0.81 \\
\hline Granger et al., 2003 & STEMI, pPCI & 960 & Infarct size & 0.76 \\
\hline APEX AMI Investigators 2007 & STEMI, pPCI & 2860 & Death, 30 days & 0.78 \\
\hline Shernan et al., 2004 & $\mathrm{CABG}_{+} /-$valve & 914 & Composite $^{2}$ & -3 \\
\hline Verrier et al., 2004 & $\mathrm{CABG}+/-$ valve & 3099 & Death/MI, 30 days & 0.07 \\
\hline Smith et al., 2011 & $\mathrm{CABG}_{+} /-$valve & 4254 & Death/MI, 30 days & 0.20 \\
\hline
\end{tabular}

${ }^{1}$ Abbreviations: STEMI: ST-elevation Myocardial Infarction. pPCI: Primary Percutaneous Coronary Intervention. CABG:

Coronary artery bypass grafting. MI: Myocardial infarction. NS: not significant

2 Death, MI, coronary heart failure, new central nervous system deficit

${ }^{3}$ Non-significant, no $\mathrm{P}$ value given 
Figure 1. Heart diseases with complement system involved in the pathophysiology. Panel A: A normal heart for comparision. Panel B: In atrial fibrillation there are multiple wavelets of electrical activation in the atria and lack of synchronous contraction. Panel C: In heart failure, the ventricles may dilate resulting in reduced pump function. Panel D: In ST elevation myocardial infarction, there is an acute occlusion of a coronary artery, due to a ruptured plaque and a superimposed thrombus. This leads to myocardial cell death and necrosis, the degree of which is related to whether and when the myocardium is reperfused. Panel E: In Chagas disease, Trypanosoma cruzi may be transmitted to humans by a Triatomine bug, giving rise to a parasitic infection of the human host. This may induce acute myocarditis, but most commonly dilated heart failure, sometimes with an aneurismatic apex, evolving after several decades.

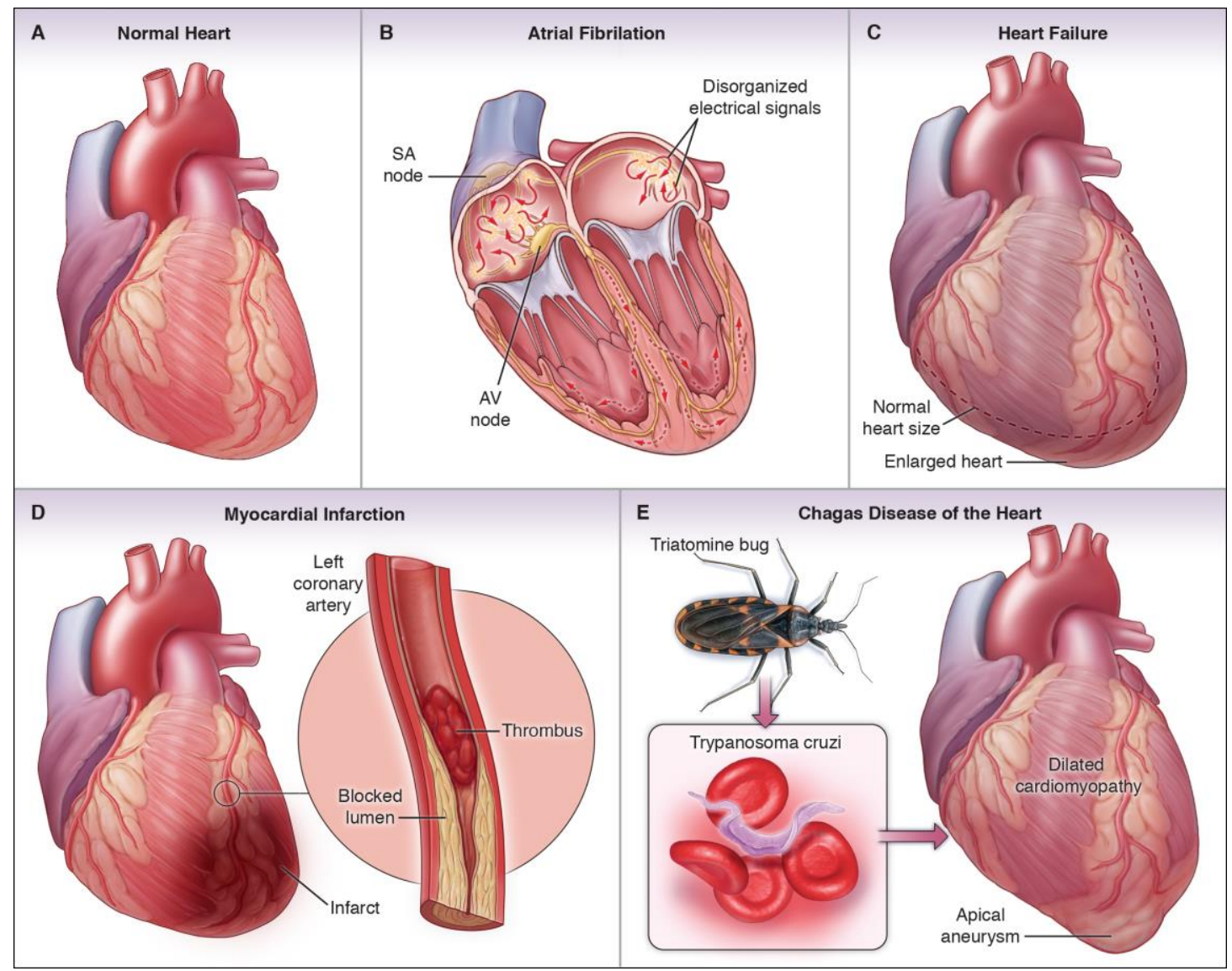


